\title{
Monkey Alarm Calling: It Ain't all Referential, or is It?
}

\author{
Claudia Fichtel
}

Behavioral Ecology \& Sociobiology

German Primate Center, Leibniz Institute for Primate Research

Leibniz Science Campus, Primate Cognition, Göttingen, Germany

*Corresponding author (Email: Claudia.Fichtel@gwdg.de)

Citation - Fichtel, C. (2020). Monkey alarm calling: It ain't all referential, or is it? Animal Behavior and Cognition, 7(2), 101-107. doi: https://doi.org/10.26451/abc.07.02.04.2020

\begin{abstract}
Cheney and Seyfarth's pioneering studies on vervet alarm calls reformed our knowledge about nonhuman's understanding of the world and their social relationships. Since then, it has been reported that some other primate species also have functionally referential alarm calls for aerial and terrestrial predators, but recent research indicates that these calls, or acoustic variants thereof, are also used in other contexts. Since the use of unspecific general alarm calls for terrestrial predators that are also used during aggressive interactions with conspecifics appears to be more common among primates, particularly in phylogenetically basal lemurs, these calls may present the ancestral form of primate alarm calling. In addition, intraspecific comparisons between populations that are exposed to different sets of predators also suggest that terrestrial predator alarm call usage and comprehension is more flexible than usage and comprehension of aerial alarm calls. Thus, primates can infer specific meaning from calls either based on their predator exposure history or by taking additional contextual information into account. The fact that they can even extract specific information from non-specific signals puts the utility of the original concept of functional reference into question.
\end{abstract}

Keywords - Nonhuman primates, Lemurs, Alarm calls, Functional referential

With their pioneering work on vervet monkey (Chlorocebus pygerythrus) alarm calls, Dorothy Cheney and Robert Seyfarth (Seyfarth et al., 1980) inspired many scholars in the field of animal communication and behavior. Through their groundbreaking approach to use playback experiments in the field, they were the first to systematically study what animal signals may mean. By combining animal focal observations with very clever and elegant field experiments, they revolutionized our understanding of nonhuman primates' knowledge of the world and their social relationships (Cheney \& Seyfarth, 1990).

Even forty years later, Cheney's and Seyfarth's contributions to our understanding of the meaning and function of animal vocalizations and their relevance for the evolution of language remain the most influential and actively debated ones. Based on the observations of Tom Struhsaker (1967) that vervet monkeys produce acoustically different alarm calls in response to different types of predators, which, in turn, elicit predator-specific escape strategies, they developed playback experiments to infer what information listeners associate with particular calls. They showed that vervet monkeys responded with different predator-specific escape strategies to recorded alarm calls given during natural encounters with snakes, leopards, and eagles (Seyfarth et al., 1980). Although no predator was present during these experiments, vervet monkeys displayed the same predator-specific escape strategies to the broadcast of alarm calls as during natural predator encounters, suggesting that they extract a specific meaning from these calls. The findings that animal signals are not merely an expression of motivational state sparked the 
interest of researchers across disciplines, including animal behavior, psychology, philosophy, and linguistics.

As convincing and elegant these playback experiments were, understanding what these calls indeed mean, was, and still is, one of the biggest challenges in the study of animal communication because a potential meaning can only be inferred by the corresponding responses of listeners. Peter Marler, Joe Macedonia and Christopher Evans subsequently introduced the term "functionally referential calls" because these calls function to provide information to listeners about external events or objects (Macedonia \& Evans, 1993; Marler et al., 1992). According to this framework, functionally referential calls require production specificity as well as acoustical distinctiveness of the respective calls (Evans, 1997; Macedonia \& Evans 1993; Marler et al., 1992).

In the following decade of research, functionally referential alarm calls were described in several other nonhuman primates, e.g., ringtailed lemurs (Lemur catta: Macedonia, 1990; Pereira \& Macedonia, 1991), Diana monkeys (Cercopithecus diana; Zuberbühler et al., 1997), Campbell's monkeys (C. campbelli; Zuberbühler, 2001), but also in birds and other mammals (Evans \& Evans, 2007; Kiriazis \& Slobodchikoff, 2006; Manser et al., 2001). However, some primate species lack predator-specific alarm calls (black-and white ruffed lemurs, Varecia variegata: Macedonia, 1990; Bonnet macaques, Macaca radiata: Ramakrishnan \& Coss, 2000; Chacma baboons, Papio ursinus: Fischer et al., 2001) or produce calls in response to various disturbances that were perceived categorically by listeners (Barbary macaques, Macaca sylvanus: Fischer, 1998). Yet other species, including redfronted lemurs (Eulemur rufifrons), Verreaux's and Coquerel's sifakas (Propithecus verreauxi, P. coquereli), exhibit a mixed alarm call system with functionally referential alarm calls only for aerial predators and general alarm calls for terrestrial predators that are also given during aggressive interactions with conspecifics (Fichtel \& Kappeler, 2002; Fichtel \& van Schaik, 2006).

Puzzled by this mix of functionally referential and unspecific general alarm calls, I studied the flexibility in usage and comprehension of general alarm calls in more detail across lemurs, our best living models of the ancestral primate condition (Yoder et al., 1996). Although about one third of all primates are nocturnal, small-bodied, and face a high predation risk (Fichtel, 2016; Isbell, 1994; Janson, 2003; Scheumann et al., 2007), their alarm-calling behavior and antipredator strategies remain less well studied (Fichtel, 2016). Small body size and nocturnality have been suggested to represent adaptations to reduce predation risk (Clutton-Brock \& Harvey, 1977). Accordingly, nocturnal species may depend on reduced detectability and crypsis, whereas diurnal species rely on early detection to ward off predators (Terborgh \& Janson, 1986). However, recent research suggests that not all nocturnal primates necessarily rely on crypsis; some also mob predators and appear to rely on a combination of alarm calls and escape responses that are adapted to the different hunting tactics of different predators (Fichtel, 2012, 2016).

Nocturnal gray mouse lemurs (Microcebus murinus) produce two types of alarm calls, "Whistles" and "Zecks," which are both also given in other contexts: "whistles" are given in response to a raptor model, during encounters with a predatory lemur species, the giant Coquerel's mouse lemur (Mirza coquereli), and in response to snakes, which mouse lemurs mob jointly (Eberle \& Kappeler, 2008), but also during mating and the reunion of group mates at the sleeping site (Braune et al., 2005; Rahlfs \& Fichtel, 2010). Hence, these calls may have an alerting recruiting function. "Zecks" are given during predator encounters but also during agonistic interactions with conspecifics or disturbances at sleeping sites. Because "zecks" are directed at predators and aggressors, they may have a primary deterrence function.

These observations suggest that both alarm call types are given in contexts that elicit similar affective or motivational states and that require similar responses, with "whistles" having a primarily alerting recruiting function and "zecks" having a primarily deterrence function. However, playback experiments with "zecks" and "whistles" of wild mouse lemurs did solely elicit an orienting response towards the sound source, but no specific escape response. Since it is challenging to video-tape responses of a small mouse lemur at night in a dense forest, we conducted the playback experiments in short-term captivity, in an outdoor aviary in camp. Hence, it is difficult to conclude whether they do not associate specific escape responses with these alarm calls or whether they may have needed additional contextual 
information to infer a potential meaning from these calls, that was not available in this experimental setting.

Nocturnal red-tailed and Sahamalaza sportive lemurs (Lepilemur ruficaudatus, L. sahamalazensis) also produce general alarm calls, which are given during predator encounters with snakes and carnivores as well as during agonistic interactions with conspecifics (Fichtel, 2007; Seiler et al., 2013). Because they did not produce alarm calls in response to playback experiments with calls from predators, which, however, elicited alarm calls in diurnal Verreaux's sifakas or cathemeral redfronted lemurs (Fichtel \& Kappeler, 2002), redtailed sportive lemurs may not rely on early warning of predators. Nonetheless, in response to playback experiments with these alarm calls, sportive lemurs exhibit predatorspecific escape strategies (Fichtel, 2007; Seiler et al., 2013). Hence, the majority of lemurs studied so far, including nocturnal lemurs, produce general alarm calls for terrestrial predators.

Interestingly, other anthropoid primates such as saddleback tamarins (Saguinus fuscicollis: Kirchhof \& Hammerschmidt, 2006) or white-faced (Cebus capucinus: Fichtel et al., 2005; Digweed et al., 2005) and tufted capuchin monkeys (Cebus apella: Wheeler, 2010) or blue monkeys (Cercopithecus mitis stuhlmanni: Papworth et al., 2008) also produce alarm calls that are given in response to terrestrial predators and during agonistic interactions with conspecifics. General alarm calls may also reflect risk urgency; either by variation in call rate in tufted capuchin monkeys (Wheeler, 2010) or by subtle changes in the acoustic structure of redfronted lemur's general alarm calls (Fichtel \& Hammerschmidt, 2002).

Interestingly, some diurnal species also produce alarm calls in response to aerial predators and acoustic variants thereof in other contexts. For example, capuchin monkeys produce two categories of alarm calls in response to predators and within- or between- group aggression (Fichtel et al., 2005). The first category consists of calls that are given in response to aerial predators, unfamiliar conspecifics, and humans. The second category consists of calls that are given in response to snakes and terrestrial predators but also during aggressive interaction with conspecifics. The two categories of alarm calls differ acoustically from each other, and within categories calls exhibit acoustic differences but also show considerable overlap in acoustic structure. Since playback experiments with alarm calls have not been conducted, it remains an open question as to whether receivers can extract a specific meaning from these calls.

In a similar vein, a recent quantitative acoustic analysis of vervet monkeys' alarm calls revealed that females' eagle and snake alarm calls and males' leopard alarm calls acoustically overlap with calls that are given during agonistic interactions among conspecifics (Price et al., 2015). According to the framework of functional reference, these calls lack production specificity, but playback experiments with alarm calls clearly showed that listeners inferred specific information from these calls (Seyfarth et al., 1980), most likely by both, cognitive appraisal of the situation and the acoustic structure of the calls (Price et al., 2015).

Notably, several primate species that have been suggested to exhibit functionally referential alarm calls produce alarm calls that belong to the call category of loud or long- distance calls that are given in response to predators, general disturbances or during intergroup communication and aggression (Wich \& Nunn, 2002). For example, male Diana monkeys produce long-distance calls, either spontaneously or in reaction to a variety of stimuli, including predators and non-predators (Zuberbühler et al., 1997). Their long-distance calls given in response to leopards (Panthera pardus) and crowned hawk eagles (Stephanoaetus coronatus) differed in several acoustic variables, but long-distance calls given in response to general disturbances, such as falling trees, appeared to overlap in their acoustic structure with longdistance eagle calls. Playback experiments with long-distance calls given to leopards and eagles elicited corresponding leopard or eagle alarm calls in conspecifics (Zuberbühler et al., 1997). Hence, as in vervet monkeys, listeners may have inferred specific information from these calls by both the context and the acoustic structure of the calls.

In a similar vein, alarm calls of putty-nosed monkeys (Cercopithecus nictitans martini) have been considered as functionally referential alarm calls (Arnold \& Zuberbühler, 2006, 2008), but more detailed studies revealed that they are not functionally referential because they are also given in non-predatory contexts, such as general disturbances (e.g., falling trees or baboon fights), thus lacking production 
specificity. However, playback experiments combining alarm calls with other contextual information showed that listeners derive information from calls by interpreting their significance using available contextual cues (Arnold \& Zuberbühler, 2013). Hence, research on several species during the last decades revealed that functionally referential alarm calls are actually also used in other contexts and that the production specificity criterion of Macedonia and Evans (1993) is not always fulfilled. Accordingly, the concept of functional reference has been critically debated (Scarantino \& Clay, 2015; Wheeler \& Fischer, 2012, 2015). Critics have argued that nonhuman primates can infer specific information from general calls by discriminating between acoustic variants of graded calls or by integrating contextual information, making the distinction between functionally referential signals and non-functionally referential calls obsolete (Wheeler \& Fischer, 2012).

In sum, many more primates actually produce alarm calls for terrestrial predators that are also used in other contexts, and a few species (capuchin, vervet, and Diana monkeys), including a nocturnal primate (gray mouse lemurs), produce aerial alarm calls that are also used in other contexts. Hence, in these species, alarm calls may have derived from calls that elicit similar affective or motivational states, which trigger context-specific corresponding alarm call variants (Fichtel et al., 2005; Price et al., 2015). For example, in capuchin monkeys, the two different categories of alarm calls are associated with different escape strategies: predators associated with the first category require different but immediate escape strategies, i.e., climbing down in response to aerial predators, hiding behind a tree trunk in response to humans, which hunt capuchin monkeys with missiles, and unfamiliar monkeys which elicit flight responses in females and males running quickly towards the challenge. In contrast, predators associated with the second category usually elicit mobbing responses (Fichtel et al., 2005). Hence, variation in specificity of alarm calls might be driven by the need to exhibit specific alarm calls that are associated with predator-specific escape strategies. However, more research on alarm calls and antipredator strategies including nocturnal primates are required to substantiate this notion.

Interestingly, flexibility in call usage and comprehension of general but not specific alarm calls has also been shown in populations that differ in the set of predators to which they are exposed (Fichtel \& Kappeler, 2011; Fichtel \& van Schaik, 2006; Stephan \& Zuberbühler, 2008). For example, two populations of Verreaux's sifakas, where one is exposed to a high density of the largest Malagasy carnivore, the fossa (Cryptoprocta ferox), but the other not, differed in call usage and comprehension of general alarm calls, but not aerial alarm calls (Fichtel \& Kappeler, 2011). The "fossa population" produced general alarm calls ("growls") in response to playback experiments with calls of the fossa or the presence of dogs, whereas the "non-fossa population" produced "tchi-faks" in response to snakes and small terrestrial predators that do not prey upon sifakas. The "fossa population" produced tchi-faks, however, when they were directly attacked by a fossa, but also during inter-group conflicts or in response to lost calls of group members. In response to playback experiments of "growls", the "fossa-population" responded as if these calls indicated the presence of the carnivore by looking down and climbing up, whereas the "non-fossa population" responded indifferently by both looking and climbing up or down. Both populations also differed in response to playback experiments with "tchi-faks"; the "fossapopulation" responded with looking up and down, climbing down and producing "growls". The "nonfossa population", however, also looked up and down, but climbed up and some individuals responded with tchi-faks. Hence, these two populations differ in call usage and comprehension.

However, in two populations of a closely related species (Coquerel's sifakas) flexibility was found only in call comprehension (Fichtel \& Kappeler, 2011; Fichtel \& van Schaik, 2006). Coquerel's sifakas also produce functionally referential aerial alarm calls and general alarm calls during terrestrial predator encounters and agonistic interactions with conspecifics (Fichtel \& Kappeler, 2011). In a wild population, where Coquerel's sifakas are exposed to aerial and terrestrial predators, and a semi-captive population, where they are exposed only to aerial predators, sifakas did not differ in their response to playback experiments with functionally referential aerial alarm calls. In contrast, Coquerel's sifakas responded strikingly differently to the broadcast of general alarm calls: in the semi-captive population, they displayed the same response as to the functional referential aerial alarm calls, i.e., by climbing down, looking up and producing aerial alarm calls, suggesting that they associate the presence of an aerial 
predator with general alarm calls. However, in the wild population, they responded as if they associate a general disturbance with these calls by looking down, climbing up and producing general alarm calls. Even though call usage did not differ between the two populations, the shift in the meaning of general alarm calls might be based on differences in predator exposure history and reflect the different outcomes of developmental processes used to acquire the association of a call with its referent (Fichtel \& Kappeler, 2011; Fichtel \& van Schaik, 2006).

Finally, male Diana monkeys differed in alarm call assemblage (i.e., usage) between two populations differing in the set of predators, with one population being exposed to eagles and leopards and the other being exposed to eagles only (Stephan \& Zuberbühler, 2008). Male Diana monkeys did not differ in their responses to eagle calls or eagle alarm calls between the two sites, but in their responses to leopard calls. In "the eagle only population," males produced more calls per sequence given to leopard calls and general disturbances than males in "the eagle and leopard population." In the latter population, call assemblage also differed between leopard and general disturbance alarm calls (Zuberbühler et al., 1997). Since call comprehension seems to be influenced by experience during ontogeny (Fichtel, 2008; Fischer et al., 2000; Seyfarth \& Cheney, 1986), differences in predator exposure history may reflect the different outcomes of developmental processes used to acquire the association of a call with its referent.

In conclusion, the use of unspecific general alarm calls for terrestrial predators appears to be more common among primates and may, because of its phylogenetic distribution among living species, present the ancestral form of alarm calling. Variation in usage and comprehension between populations that are exposed to a different set of predators suggest that the usage and comprehension of general alarm calls appears to be more flexible than that of aerial alarm calls. The flexibility to infer a specific meaning from calls is either based on predator exposure history or by including additional contextual information, indicating that the original concept of functional reference is obsolete and that nonhuman primates can extract specific meaning even from non-specific signals via pragmatic inference (Seyfarth \& Cheney, 2003, 2017a, b).

\section{References}

Arnold, K., \& Zuberbühler, K. (2006). The alarm calling system of adult male putty-nosed monkeys (Cercopithecus nictitans martini). Animal Behaviour, 72, 643-653.

Arnold, K., \& Zuberbühler, K. (2008). Meaningful call combinations in a non-human primate. Current Biology, 18, R202-R204.

Arnold, K., \& Zuberbühler, K. (2013). Female putty-nosed monkeys use experimentally altered contextual information to disambiguate the cause of male alarm calls. PLoS One, 8, 358 e65660.

Braune, P., Schmidt, S., \& Zimmermann, E. (2005). Spacing and group coordination in a nocturnal primate, the golden brown mouse lemur (Microcebus ravelobensis) the role of olfactory and acoustic signals. Behavioral Ecology and Sociobiology, 58, 587-596.

Cheney, D. L., \& Seyfarth, R. M. (1990). How monkeys see the world: Inside the mind of another species. University of Chicago Press.

Clutton-Brock, T. H., \& Harvey, P. H. (1977). Primate ecology and social organization. Journal of Zoology, London, $183,1-39$.

Digweed, S., Fedigan, L., \& Rendall, D. (2005). Variable specificity in the anti-predator vocalizations and behaviour of the white-faced capuchin, Cebus capucinus. Behaviour, 142, 997-1021.

Eberle, M., \& Kappeler, P. M. (2008). Family insurance: Kin selection and cooperative breeding in a solitary primate (Microcebus murinus). Behavioral Ecology and Sociobiology, 60, 582-588.

Evans, C. S. (1997). Referential signals. In D. H. Owings, M. D. Beecher, \& N. S. Thompson (Eds.), Perspectives in ethology, Vol. 12. Communication (pp. 99-143). Plenum.

Evans, C., \& Evans, L. (2007). Representational signalling in birds. Biology Letters, 3, 8-11.

Fichtel, C. (2007). Avoiding predators at night: Antipredator strategies in red-tailed sportive lemurs (Lepilemur ruficaudatus). American Journal of Primatology, 69, 611-624.

Fichtel, C. (2008). Ontogeny of conspecific and heterospecific alarm call recognition in wild Verreaux's sifakas (Propithecus verreauxi verreauxi). American Journal of Primatology, 70, 127-135. 
Fichtel, C. (2012). Predation. In J. C., Mitani, J. Call, P. Kappeler, R. Palombit, \& J. Silk (Eds.), The evolution of primate societies (pp. 169-194). University of Chicago Press.

Fichtel, C. (2016). Predation in the dark: Antipredator strategies of Cheirogaleidae and other nocturnal primates. In S. Lehman, U. Radespiel, \& E. Zimmerman (Eds.), The dwarf and mouse lemurs of Madagascar. Biology, behavior and conservation biogeography of the Cheirogaleidae (pp. 366-380). Cambridge University Press.

Fichtel, C., \& Hammerschmidt, K. (2002). Responses of redfronted lemurs to experimentally modified terrestrial alarm calls: Evidence for urgency-based changes in call structure. Ethology, 108, 763-777.

Fichtel, C., \& Kappeler, P. M. (2002). Anti-predator behavior of group living Malagasy primates: Mixed evidence for a referential alarm call system. Behavioral Ecology and Sociobiology, 51, 262-275.

Fichtel, C., \& Kappeler, P. M. (2011). Variation in the meaning of alarm calls in Verreaux's and Coquerel's sifakas (Propithecus verreauxi, P. coquereli). International Journal of Primatology, 32, 346-361.

Fichtel, C., \& van Schaik, C. P. (2006). Semantic differences in Sifaka (Propithecus verreauxi) alarm calls: A reflection of genetic or cultural variants? Ethology, 112, 839-849.

Fichtel, C., Perry, S., \& Gros-Louis, J. (2005). Alarm calls of white-faced capuchin monkeys: An acoustic analysis. Animal Behaviour, 70, 165-176.

Fischer, J. (1998). Barbary macaques categorize shrill barks into two call types. Animal Behaviour, 55, $799-807$.

Fischer, J., Cheney, D. L., \& Seyfarth, R. M. (2000). Development of infant baboons' responses to graded bark variants. Proceedings of the Royal Society London, B, 267, 2317-2321.

Fischer, J., Metz, M., Cheney, D., \& Seyfarth, R.M. (2001). Baboon responses to graded bark variants. Animal Behaviour, 61, 925-931.

Isbell, L. (1994). Predation on primates: Ecological patterns and evolutionary consequences. Evolutionary Anthropology: Issues, News, and Reviews, 3, 61-71.

Janson C. (2003). Puzzles, predation, and primates: Using life history to understand selection pressures. In P. M. Kappeler \& M. E. Pereira (Eds.), Primate life histories and socioecology. (pp. 103-131). University of Chicago Press.

Kiriazis, J., \& Slobodchikoff, C. (2006). Perceptual specificity in the alarm calls of Gunnison's prairie dogs. Behavioural Processes, 73, 29-35.

Kirchhof, J., \& Hammerschmidt, K. (2006). Functionally referential alarm calls in tamarins (Saguinus fuscicollis and Saguinus mystax)- Evidence from playback experiments. Ethology, 112, 346-354.

Macedonia, J. M. (1990). What is communicated in the antipredator calls of lemurs: Evidence from playback experiments with ringtailed and ruffed lemurs. Ethology, 86, 177-190.

Macedonia, J. M., \& Evans, C. S. (1993). Variation among mammalian alarm call systems and the problem of meaning in animal signals. Ethology, 93, 177-197.

Manser, M., Bell, M., \& Fletcher, L. (2001). The information that receivers extract from alarm calls in suricates. Proceedings of the Royal Society London, B, 268, 2485-2491

Marler, P., Evans, C. S., \& Hauser, M. D. (1992). Animal signals: Motivational, referential, or both? In H. Papousek, U. Jürgens, \& M. Papousek, (Eds.), Nonverbal vocal communication (pp. 66-86). Cambridge University Press.

Papworth, S., Böse, A.-S., Barker, J., Schel, A. M., \& Zuberbühler, K. (2008). Male blue monkeys alarm call in response to danger experienced by others. Biology Letters, 4, 472-475.

Pereira, M. E., \& Macedonia, J. M. (1991). Ringtailed lemur anti-predator calls denote predator class, not response urgency. Animal Behaviour, 41, 543-544.

Price, T., Wadewitz, P., Cheney, D. L., Seyfarth, R. M., Hammerschmidt, K., \& Fischer, J. (2015). Vervets revisited: A quantitative analysis of alarm call structure and context specificity. Scientific Reports, 5, 13220.

Rahlfs, M., \& Fichtel, C. (2010). Anti-predator behaviour in a nocturnal primate, the grey mouse lemur (Microcebus murinus). Ethology, 116, 429-439.

Ramakrishnan, U., \& Coss, R. G. (2000). Recognition of heterospecific alarm vocalizations by bonnet macaques (Macaca radiata). Journal of Comparative Psychology 114, 3-12.

Scarantino, A., \& Clay, Z. (2015). Contextually variable signals can be functionally referential. Animal Behaviour, 100, e1-e8.

Scheumann, M., Rabesandratana, B., \& Zimmermann, E. (2007). Predation, communication, and cognition in lemurs. In S. Gursky \& K. A. I . Nekaris (Eds.), Primate anti-predator strategies (pp. 100-126). Springer.

Seiler, M., Schwitzer, C., \& Holderied, M. (2013). Anti-predator behaviour of Sahamalaza sportive lemurs, Lepilemur sahamalazensis, at diurnal sleeping sites. Contributions to Zoology, 82, 131-143. 
Seyfarth, R. M., \& Cheney, D. (1986). Vocal development in vervet monkeys. Animal Behaviour, 34, 1640-1658.

Seyfarth R. M., \& Cheney D. L. (2003). Signalers and receivers in animal communication. Annual Review of Psychology, 24, 145-173.

Seyfarth, R. M., \& Cheney, D. L. (2017a). The origin of meaning in animal signals. Animal Behaviour, 124, 339346.

Seyfarth R. M, Cheney D. L. (2017b). Precursors to language: Social cognition and pragmatic inference in primates. Psychonomic Bulletin \& Review, 24, 79-84.

Seyfarth, R. M., Cheney, D. L., \& Marler, P. (1980). Monkey responses to three different alarm calls: Evidence of predator classification and semantic communication. Science, 210, 801-803.

Stephan, C., \& Zuberbühler, K. (2008). Predation increases acoustic complexity in primate alarm calls. Biology Letters, 4, 641-644.

Struhsaker, T. T. (1967). Auditory communication among vervet monkeys (Cerpithecus aethiops). In S. A. Altmann (Ed.), Social communication among primates (pp. 281-384). University of Chicago Press.

Terborgh, J., \& Janson, C. H. (1986). The socioecology of primate groups. Annual Review of Ecological Systems 17, $111-135$.

Wheeler, B. C. (2010). Production and perception of situationally variable alarm calls in wild tufted capuchin monkeys (Cebus apella nigritus). Behavioral Ecology and Sociobiology, 64, 989-1000.

Wheeler, B. C., \& Fischer, J. (2012) Functionally referential signals: A promising paradigm whose time has passed. Evolutionary Anthropology, 21, 195-205.

Wheeler, B. C., \& Fischer, J. (2015). The blurred boundaries of functional reference: A response to Scarantino \& Clay. Animal Behaviour, 100, e9-e13.

Wich, S., \& Nunn, C. (2002). Do male "long-distance calls" function in mate defense? A comparative study of longdistance calls in primates. Behavioral Ecology and Sociobiology, 52, 474-484.

Zuberbühler, K., Noe, R., \& Seyfarth, R. (1997). Diana monkey long-distance calls: Messages for conspecifics and predators. Animal Behaviour, 53, 589-604.

Yoder, A. D., Cartmill, M., Ruvolo, M., Smith, K., \& Vilgalys, R. (1996). Ancient single origin for Malagasy primates. Proceedings of the National Academy of Sciences of the United States of America, 93, 51225126. 